\title{
Role of hysteroscopy for diagnosis and treatment of uterine factors affecting subfertility
}

\author{
Nayana D. H., Shreya S.*
}

Department of Obstetrics and Gynecology, Rajarajeshwari Medical College, Bengaluru, Karnataka, India

Received: 28 June 2018

Revised: 28 July 2018

Accepted: 05 October 2018

\section{*Correspondence:}

Dr. Shreya S.,

E-mail:dh.nayana@gmail.com

Copyright: () the author(s), publisher and licensee Medip Academy. This is an open-access article distributed under the terms of the Creative Commons Attribution Non-Commercial License, which permits unrestricted non-commercial use, distribution, and reproduction in any medium, provided the original work is properly cited.

\section{ABSTRACT}

Background: Hysteroscopy has become the gold standard for diagnosis of intrauterine abnormalities. Intrauterine lesions such as adhesions, uterine septum polyps or submucous myomas are diagnosed much more precisely by hysteroscopy and are detectable in 10-15\% of women seeking treatment for subfertility. The present study analyses various etiological factors in infertility diagnosed by hysteroscopy and to evaluate therapeutic interventions done during hysteroscopy.

Methods: The cases for the study will include all women with primary or secondary infertility admitted in tertiary health centre from April 2016 to May 2018 for hysteroscopy.

Results: Out of 90 subjects $66(73.3 \%)$ were primary infertility and 24 (26.7\%) were secondary infertility. Out of 90 cases studied, $68(75.6 \%)$ had normal findings, $10(11.1 \%)$ had endometrial polyps, $01(1.1 \%)$ had submucous fibroid, $5(5.6 \%)$ had septate uterus, hyperplastic endometrium in $3(3.3 \%)$ and atropic endometrium in $1(1.1 \%)$, intrauterine adhesions and hypoplastic uterus in 1 each. Hysteroscopic interventions were performed in the form of curettage in 08 $(33.3 \%)$, hysteroscopic cannulation in 2 (8.3\%), polypectomy and septal resection in 5 (20.8\%) cases each, submucosal fibroid resection in $1(4.2 \%)$ cases, tubal block released in $2(8.3 \%)$.

Conclusions: Hysteroscopy was found the best method in evaluation of intrauterine conditions for subfertility and also the type and location of uterine abnormalities can be precisely noted. The removal of those changes during operative hysteroscopy increases the fertility rate in women treated during this procedure.

Keywords: Endometrial polyps, Hysteroscopy, Infertility, Subfertility

\section{INTRODUCTION}

One of the most important and underappreciated reproductive health problems in developing countries is the high rate of infertility. The inability to procreate is frequently considered a personal tragedy and a curse for the couple, impacting severely on the entire family.

Infertility affects about $10-15 \%$ of reproductive age couples. Although the prevalence of infertility is believed to have remained relatively stable during past 40 years, the demand for evaluation and infertility treatment has increased. ${ }^{1,2}$ Majority of pelvic pathology is frequently not well appreciated by routine pelvic examinations and the usual diagnostic procedures. Hysteroscopy becomes the "third eye" of the gynaecologist in diagnosis of infertility. visualising the uterine cavity and identifying the possible pathology has made hysteroscopy an equally important tool in infertility evaluation. Hysteroscopy has become the gold standard for diagnosis of intrauterine abnormalities. Small intrauterine lesions such as adhesions, polyps or submucous myomas are diagnosed much more precisely by hysteroscopy. Hysteroscopy is considered a minimally invasive approach which can be used for analysis and treatment of numerous intrauterine and endocervical problems. The advantage of this method 
is the direct view and simultaneous intervention. Hence, Hysteroscopy is an effective and safe tool in comprehensive evaluation of infertility.

\section{METHODS}

This cross-sectional study was done for period of two years in department of Obstetrics and Gynecology in tertiary care hospital from April 2016 to May 2018.

Study design: diagnostic study; sample size: 90.

\section{Inclusion criteria}

- Women with primary or secondary infertility admitted in hospital for hysteroscopy.

\section{Exclusion criteria}

- Active pelvic infections

- Medical disorders which are contraindication for anaesthesia.

Prior to commencement of the study, ethical clearance was obtained from Human Ethics Committee. A total of 90 women aged between 18-40 years with primary or secondary infertility willing for the infertility workup were included in study. A detailed medical history was taken in all cases. This was followed by a detailed medical examination and relevant examination of the husband.

Patients satisfying the selection criteria were informed in detail about the nature of study and a written informed consent was obtained prior to procedure. After admission demographic data such as age, religion, education, socioeconomic status was obtained. A detailed history and clinical examination were done.

The schedule of investigations done to determine fitness for surgery. Patient was admitted one day prior to the procedure and pre-anaesthetic checkup was done. Hysteroscopy was scheduled in pre-ovulatory period between day 5 to day 10 of cycle for infertility evaluation after informed consent.

Hysteroscopy was done under general anaesthesia after the opinion of the anaesthetist. In hysteroscopy, uterine cavity was examined for the presence of septum, any congenital malformation, fibrotic bands, polyps, myomas, endometrial appearance, thickness and color. Endocervical canal was visualized for any growth or polyps. Both the tubal ostia were visualized.

Surgical interventions were carried out whenever required during the procedure such as hysteroscopic interventions such as intrauterine adhesiolysis, hysteroscopic polypectomy, hysteroscopic septal resection, endometrial curettage, cannulation, hysteroscopic submucosal fibroid resection etc. was carried out. Patient was kept for a period of 24 hours in the hospital post-operatively.

\section{RESULTS}

Out of 90 subjects $66(73.3 \%)$ were primary infertility and $24(26.7 \%)$ were secondary infertility.

Table 1: Distribution according to age and type of infertility in the study subjects.

\begin{tabular}{|llll|}
\hline $\begin{array}{l}\text { Age group } \\
\text { (in years) }\end{array}$ & $\begin{array}{l}\text { Primary } \\
\text { infertility }\end{array}$ & $\begin{array}{l}\text { Secondary } \\
\text { infertility }(\%)\end{array}$ & Total \\
\hline$\leq 25$ & $29(78.4)$ & $08(21.6)$ & $37(41.1)$ \\
\hline $26-30$ & $23(67.6)$ & $11(32.4)$ & $34(37.8)$ \\
\hline $31-35$ & $10(66.7)$ & $05(33.3)$ & $15(16.7)$ \\
\hline$>35$ & $04(4.4)$ & 0 & $04(4.4)$ \\
\hline Total & $66(73.3)$ & $24(26.7)$ & $90(100)$ \\
\hline
\end{tabular}

In $68(75.6 \%)$ cases, the duration of infertility was less than 5 years. Amongst 68 cases primary infertility were $58(85.3 \%)$ and secondary infertility were $10(14.7 \%)$. In $18(20.0 \%)$ cases, the duration of infertility was from 6 to 10 years. Amongst 18 cases primary infertility were 06 $(33.3 \%)$ and $12(66.7 \%)$ were with secondary infertility. In $04(4.4 \%)$ case, the duration of infertility was from 10 to 15 years where $02(50.0 \%)$ was with primary infertility $02(50.0 \%)$ was with secondary infertility. Mean duration of infertility in primary infertility group is $3.77 \pm 2.52$ years and in secondary infertility group is $6.17 \pm 2.51$ years.

\section{Findings on hysteroscopy}

Out of 90 cases studied, 68 (75.6\%) had normal findings, $10(11.1 \%)$ had endometrial polyps, $01(1.1 \%)$ had submucous fibroid, $5(5.6 \%)$ had septate uterus, hyperplastic endometrium in $3(3.3 \%)$ and atropic endometrium in $1(1.1 \%)$, intrauterine adhesions and hypoplastic uterus in 1 each.

Table 2: Distribution according to hysteroscopy in the study subjects.

\begin{tabular}{|lll|}
\hline Hysteroscopy & Number & Percentage \\
\hline Normal & 68 & 82.2 \\
\hline Endometrial polyps & 10 & 11.1 \\
\hline Endometrium hyperplastic & 03 & 03.3 \\
\hline Atropic endometrium & 01 & 01.1 \\
\hline Hypoplastic uterus & 01 & 01.1 \\
\hline Partial septum present & 05 & 05.6 \\
\hline Submucous fibroid & 01 & 01.1 \\
\hline Intrauterine adhesions & 01 & 01.1 \\
\hline Total & 90 & 100.0 \\
\hline
\end{tabular}

Hysteroscopic interventions were performed in the form of curretage in 08 (33.3\%), hysterocopic cannulation in 2 $(8.3 \%)$, polypectomy and septal resection in $5(20.8 \%)$ cases each, submucosal fibroid resection in $1(4.2 \%)$ cases, tubal block released in $2(8.3 \%)$. 
Table 3: Distribution according to hysteroscopic interventions in the study subjects.

\begin{tabular}{|lll|}
\hline Hysteroscopic interventions & Number & Percentage \\
\hline Diagnostic & 66 & 66.6 \\
\hline Curettage & 08 & 8.8 \\
\hline Hysteroscopic cannulation & 02 & 2.2 \\
\hline Polpectomy & 05 & 5.5 \\
\hline Septal resection & 05 & 5.5 \\
\hline Submucosal fibroid resection & 01 & 1.1 \\
\hline Tubal block released & 02 & 2.2 \\
\hline Adhesiolysis & 01 & 1.1 \\
\hline Total & 90 & 100.0 \\
\hline
\end{tabular}

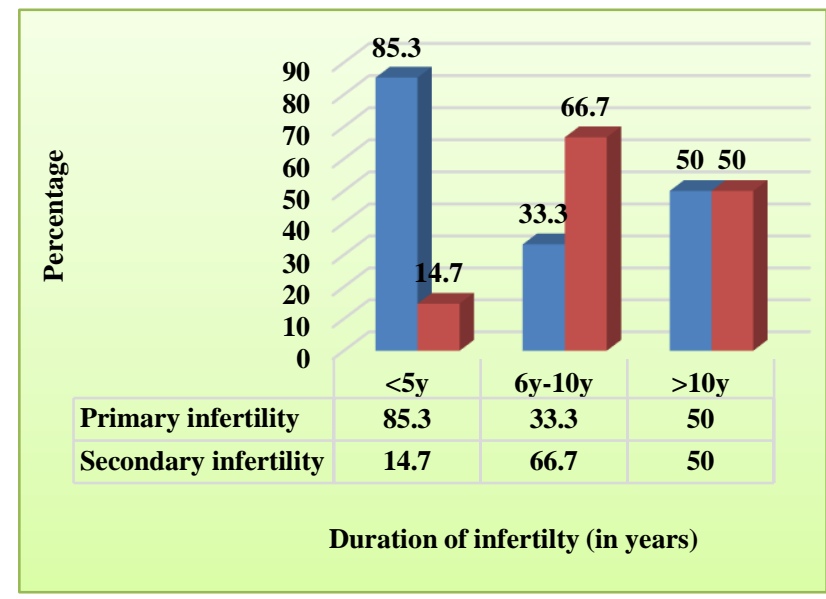

Figure 1: Bar diagram showing the distribution according to hysteroscopic interventions in the study subjects.

\section{DISCUSSION}

Present study was cross-sectional study done for period of two years in department of Obstetrics and Gynecology in a tertiary care centre from April 2016 to May 2018. Following conclusions are derived from hysteroscopy study of 90 cases of infertility were drawn:
Table 4: Type and duration of infertility and mean age of infertility.

\begin{tabular}{|c|c|c|}
\hline Type of infertility & Primary & Secondary \\
\hline Puri S et $\mathrm{al}^{3}$ & $24(48 \%)$ & $26(52 \%)$ \\
\hline Zhang E et al ${ }^{4}$ & $71(53.8 \%)$ & $61(46.2 \%)$ \\
\hline Elbareg $\mathrm{AM}^{5}$ & $130(65 \%)$ & $70(35 \%)$ \\
\hline Present study & $66(73.3 \%)$ & $24(26.7 \%)$ \\
\hline
\end{tabular}

In present study out of 90 subjects $66(73.3 \%)$ were primary infertility and $24(26.7 \%)$ were secondary infertility which is comparable to study by Elbareg AM et al. ${ }^{5}$ Boricha YG et al, primary infertility was prevalent between the age group of 21 to 25 years, 15 cases $(42.85 \%)$ and secondary infertility between age group 26 to 35 years, 6 cases $(40 \%)$ respectively. ${ }^{6}$

Present study showed mean age of primary infertility is $27.00 \pm 5.31$ years, and that of secondary infertility was $27.79 \pm 3.38$ years which is comparable to study by Kore $S$ et al where most of the women were between 25-30 years. Mean duration of infertility in primary infertility group is $3.77 \pm 2.52$ years and in secondary infertility group is $6.17 \pm 2.51$ years. This shows increased incidence of diagnostic methods leading to increased incidence and also awareness of infertility problem.

In Zhang E et al study the patients in secondary infertility group were elder compared to primary infertility group $(30.15 \pm 4.54$ vs $32.84 \pm 5.25$ years) when compared to present study the subjects were younger compared to other studies. ${ }^{4}$

\section{Obstetric history in secondary infertility}

In study by Dhont N $13 \%$ of women in secondary infertile relationships were nulliparous, $70 \%$ had not more than one pregnancy and $44 \%$ had no living children. $^{7}$ In present study out of 24 cases of secondary infertility, more than half the secondary infertility group had previous history of miscarriage.

Table 5: Hysteroscopic findings.

\begin{tabular}{|c|c|c|c|c|c|}
\hline Study (hysteroscopic findings) & Nayak PK et al ${ }^{8}$ & Zhang E et $\mathrm{al}^{4}$ & Elbareg et al $^{5}$ & Vaid $\mathrm{K}$ et $\mathrm{al}^{9}$ & Present study \\
\hline Intrauterine adhesions & $1(<01 \%)$ & $3.79 \%$ & $14 \%$ & $23(11.91)$ & $1(1.1 \%)$ \\
\hline Polyps & $16(05 \%)$ & $39.9 \%$ & $10 \%$ & $8(4.14 \%)$ & $10(11.1)$ \\
\hline Submucous fibroid & $8(03 \%)$ & $0.76 \%$ & $4 \%$ & $4(2.07 \%)$ & $1(1.1 \%)$ \\
\hline Septum & $29(10 \%)$ & $9.09 \%$ & - & $5(2.59 \%)$ & $5(5.6 \%)$ \\
\hline Endometrial abnormality & $6(02 \%)$ & - & $3 \%$ & $7(3.62 \%)$ & $4(4.4 \%)$ \\
\hline Small uterus & 0 & 0 & - & $3(1.55 \%)$ & $1(1.1 \%)$ \\
\hline
\end{tabular}

The commonest hysteroscopic uterine cavity abnormality was endometrial polyp seen in $10 \%$. The same is observed in studies done by Zhang E et al, Nayak PK et al and Elbareg AM et al. The second most common hysteroscopic uterine cavity abnormality in present study was septate uterus which was similar to study by Nayak 
PK et al where septate uterus was found at higher incidence of $10 \%$ in their study.

In study by Elbareg AM et al significant hysteroscopy findings were noted in $50 \%$ of cases, in present study significant findings were noted in $24.4 \%$. In present study diagnostic hysteroscopy was performed in 66 patients $(73.3 \%)$ and operative hysteroscopy in 24 patients. Various interventions were done as follows:

Table 6: Hysteroscopic interventions.

\begin{tabular}{|llll|}
\hline Curettage & $\begin{array}{l}\text { Singh R Vaid K } \\
\text { et al }\end{array}$ & $\begin{array}{l}\text { Present } \\
\text { study }\end{array}$ \\
\hline $\begin{array}{l}\text { Hysteroscopic } \\
\text { cannulation }\end{array}$ & $17 \%$ & - & $8(8.8 \%)$ \\
\hline $\begin{array}{l}\text { Polpectomy } \\
\text { Septal resection }\end{array}$ & $06 \%$ & $8(4.14 \%)$ & $2(2.2 \%)$ \\
\hline $\begin{array}{l}\text { Submucosal fibroid } \\
\text { resection }\end{array}$ & - & $10(5.18 \%)$ & $5(5.6 \%)$ \\
\hline Tubal hydrotubation & - & - & $5(5.6 \%)$ \\
\hline Adhesiolysis & $08 \%$ & $20(10.36 \%)$ & $1(1.1 \%)$ \\
\hline Metroplasty & - & $1(0.51 \%)$ & - \\
\hline
\end{tabular}

\section{Endometrial polyps and infertility: polypectomy}

Śpiewankiewicz et al conducted a retrospective study of 78 patients, a pregnancy rate of $78.3 \%$ was noted after polypectomy compared to a pregnancy rate $42.1 \%$ in patients with normal uterine cavities. Similarly, El-Shafei et al reported natural conception rates $50 \%$ after resection of endometrial polyps. ${ }^{10-12}$ It has been associated with increased miscarriage rates, but there is no evidence of lower pregnancy rates (Bozdag et al, Pundir and Toukhy). ${ }^{13}$

A recent Cochrane review tried to assess the effect of hysteroscopic polypectomy on the results of intrauterine insemination (IUI). Apparently, the hysteroscopic removal of polyps prior to IUI increases the odds of clinical pregnancy compared to diagnostic hysteroscopy and polyp biopsy only. ${ }^{14}$ In present study polypectomy was done in $5.55 \%$ cases which is comparable to study by Vaid K et al.

\section{Uterine anomalies and infertility: resection of septum and metroplasty}

Similar to present study, studies conducted by Godinjak $\mathrm{Z}$ et al, Puri $\mathrm{S}$ et al, Jasmina et al showed that most common uterine pathology found in hysteroscopy was septate uterus and many of times uterine anomalies which are undiagnosed by prior ultrasonography is picked up by hysterolaproscopy. ${ }^{3,15}$

De Franciscis et al enrolled 44 women with uterine septae and otherwise unexplained infertility. In the 12 months of follow-up, $38.6 \%$ of septal resection patients spontaneously conceived. ${ }^{16}$
Homer et al compares reproductive performance before and after hysteroscopic metroplasty; the overall results show an impressive improvement in fertility after surgery. However, in present study septal resection was done in $5.5 \%$ and metroplasty was not done in any case. ${ }^{15-17}$

\section{Fibroids and infertility: myomectomy}

Bosteels et al performed review in order to examine efficacy of hysteroscopic removal of submucous fibroids. For a fibroid of $4 \mathrm{~cm}$, there was a marginally benefit from myomectomy when compared with expectant management. ${ }^{18}$ In present study hysteroscopic submucosal fibroid removal was done in $1.1 \%$ for a fibroid of 2-3 cm.

\section{Tubal block and infertility: tubal cannulation and hydrotubation}

Tubal cannulation: Hou Y et al included 168 women of which $107(63.7 \%)$ had bilateral proximal obstruction and $61(36.3 \%)$ had unilateral obstruction. The successful recanalization rate was $54.2 \%$ per tube and $61.9 \%$ per patient. Also, there was significant improvement in the pregnancy rate later. ${ }^{19}$

In present study tubal cannulation was performed hysteroscopically in $2(2.2 \%)$ cases out of 90 cases, compared to Keya et al where hysteroscopic cannulation was performed in $8 \% .^{9}$

Hydrotubation: Another method for tubal block release is hydrotubation. In study conducted by Adesiyun AG they analyzed that 250 patients had hydrotubation. Over 7.5 years they found that with good case selection, therapeutic hydrotubation may be beneficial in resource poor countries. ${ }^{20}$ In present study tubal block was released by hydrotubation in $2.22 \%$.

\section{CONCLUSION}

Hysteroscopy was found the best method in evaluation of intrauterine conditions for subfertility and also the type and location of uterine abnormalities can be precisely noted. Performing hysteroscopy as "one time approach" in the assessment of female infertility caused due to uterine pathology, helps in diagnosing of certain factors causing infertility, which cannot be diagnosed by any other method such as by USG, HSG and reveals whether surgery is possible and if so the nature of surgery most suited for the patient also sometimes corrective surgery can be performed simultaneously at same time. At first glance, hysteroscopy may appear to be costlier, invasive, but in the long run, it will become more beneficial.

The removal of those changes during operative hysteroscopy increases the fertility rate in women treated during this procedure. 
Funding: No funding sources

Conflict of interest: None declared

Ethical approval: The study was approved by the Institutional Ethics Committee

\section{REFERENCES}

1. Ombelet W, Cooke I, Dyer S, Serour G, Devroey P. Infertility and the provision of infertility medical services in developing countries. Human Reprod Update. 2008;14(6):605-21.

2. Dyer SJ. International estimates on infertility prevalence and treatment seeking: potential need and demand for medical care. Human Reprod. 2009;24(9):2379-80.

3. Puri S, Jain D, Puri S, Kaushal S, Deol SK. Laparohysteroscopy in female infertility: a diagnostic cum therapeutic tool in Indian setting. Int J Applied Basic Med Res. 2015;5(1):46-8.

4. Zhang E, Zhang Y, Fang L, Li Q, Gu J. Combined hysterolaparoscopy for the diagnosis of female infertility: a retrospective study of 132 patients in china. Materia Socio-medica. 2014;26(3):156-7.

5. Elbareg AM, Essadi FM, Elmehashi MO, Anwar KI. Hysteroscopy in Libyan women with recurrent pregnancy loss. Sudan Med Sci. 2014 Dec 1;9(4).

6. Boricha YG, Sharma RK, Boricha BG, Sabrina, Archanachaterjee, et al. Laproscopy in 50 infertile couples prospective study. IJMCU. 2011;2(2):66-9.

7. Dhont N, Luchters S, Muvunyi C, Vyankandondera J, De Naeyer L, Temmerman M, et al. The risk factor profile of women with secondary infertility: an unmatched case-control study in Kigali, Rwanda. BMC Women's Health. 2011;11(1):32.

8. Nayak PK, Mahapatra PC, Mallick JJ, Swain S, Mitra S, Sahoo J. Role of diagnostic hysterolaparoscopy in the evaluation of infertility: A retrospective study of 300 patients. J Human Reprod Sci. 2013;6(1):32-4.

9. Vaid K, Mehra S, Verma M, Jain S, Sharma A, Bhaskaran S. Pan endoscopic approach "hysterolaparoscopy" as an initial procedure in selected infertile women. JCDR. 2014;8(2):95-8.

10. Varasteh NN, Neuwirth RS, Levin B, Keltz MD. Pregnancy rates after hysteroscopic polypectomy and myomectomy in infertile women. Obstet Gynecol. 1999;94(2):168-71.
11. Spiewankiewicz B, Stelmachow J, Sawicki W, Cendrowski K, Wypych P, Swiderska K. The effectiveness of hysteroscopic polypectomy in cases of female infertility. Clin Exp Obstet Gynecol. 2003;30(1):23-5.

12. Shokeir TA, Shalan HM, El-Shafei MM. Significance of endometrial polyps detected hysteroscopically in eumenorrheic infertile women. J Obstet Gynaecol Res. 2004;30(2):84-9.

13. Singh R, Singh S, Yadav P, Goyal M. Role of laparohysteroscopy in management of infertile women. J Evol Med Dental Sci. 2013;2(12):1792-5.

14. Bosteels J, Kasius JC, Weyers S, Broekmans FJ, Mol $\mathrm{BW}$, D'Hooghe T. Hysteroscopy for treating subfertility associated with suspected major uterine cavity abnormalities. Cochrane Database of Systematic Reviews. 2013;1(1).

15. Godinjak Z, Idrizbegovic E. Should diagnostic hysteroscopy be a routine procedure during diagnostic laparoscopy in infertile women? Bosnian J Basic Med. 2008;8:44-7.

16. Mollo A, De Franciscis P, Colacurci N, Cobellis L, Perino A, Venezia R, et al. Hysteroscopic resection of the septum improves the pregnancy rate of women with unexplained infertility: a prospective controlled trial. Fertil Steril. 2009 Jun 1;91(6):2628-31.

17. Homer HA, Li TC, Cooke ID. The septate uterus: a review of management and reproductive outcome. Fertil Steril. 2000;73(1):1-4.

18. Bosteels J, Van Herendael B, Weyers S, D'Hooghe $\mathrm{T}$. The position of diagnostic laparoscopy in current fertility practice. Hum Reprod Update. 2007 Jun 11.

19. Hou HY, Chen YQ, Li TC, Hu CX, Chen X, Yang $\mathrm{ZH}$. Outcome of laparoscopy-guided hysteroscopic tubal catheterization for infertility due to proximal tubal obstruction. J Minim Invasive Gynecol. 2014;21(2):272-8.

20. Adesiyun AG, Cole B, Oqwuche P. Hydrotubation in the management of female infertility: outcome in low resource settings. East Afr Med J. 2009;86(1):31-6.

Cite this article as: Nayana DH, Shreya S. Role of hysteroscopy for diagnosis and treatment of uterine factors affecting subfertility. Int J Reprod Contracept Obstet Gynecol 2018;7:4882-6. 